\title{
Effect of different types of prosthetic platforms on stress-distribution in dental implant-supported prostheses
}

\author{
Lurian Minatel a , Fellippo Ramos Verri ${ }^{\mathrm{b}}$, Guilherme Abu Halawa Kudo a , Daniel Augusto de Faria Almeida ${ }^{\mathrm{b}}$, \\ Victor Eduardo de Souza Batista ${ }^{\text {b }}$, Cleidiel Aparecido Araujo Lemos ${ }^{\text {b }}$, \\ Eduardo Piza Pellizzer ${ }^{\text {b }}$, Joel Ferreira Santiago Junior ${ }^{\mathrm{a}, *}$ \\ a Pró-Reitoria de Pesquisa e Pós-graduação (PRPPG), Universidade do Sagrado Coração, USC, 10-50 Irmã Armindal, Jardim Brasil, Bauru, 17011-160, SP, Brazil \\ b Department of Dental Materials and Prosthodontics, Araçatuba Dental School, UNESP - Univ Estadual Paulista, 1193 José Bonifácio Street, Vila Mendonça, Araçatuba 16015-050, Brazil
}

\section{A R T I C L E I N F O}

\section{Article history:}

Received 31 March 2016

Received in revised form 17 September 2016

Accepted 27 September 2016

Available online 28 September 2016

\section{Keywords:}

Dental implant

Bone tissue

Mechanical stress

Finite element analysis

\begin{abstract}
A B S T R A C T
A biomechanical analysis of different types of implant connections is relevant to clinical practice because it may impact the longevity of the rehabilitation treatment. Therefore, the objective of this study is to evaluate the Morse taper connections and the stress distribution of structures associated with the platform switching (PSW) concept. It will do this by obtaining data on the biomechanical behavior of the main structure in relation to the dental implant using the 3-dimensional finite element methodology. Four models were simulated (with each containing a single prosthesis over the implant) in the molar region, with the following specifications: M1 and M2 is an external hexagonal implant on a regular platform; M3 is an external hexagonal implant using PSW concept; and M4 is a Morse taper implant. The modeling process involved the use of images from InVesalius CT (computed tomography) processing software, which were refined using Rhinoceros 4.0 and SolidWorks 2011 CAD software. The models were then exported into the finite element program (FEMAP 11.0) to configure the meshes. The models were processed using NeiNastram software. The main results are that M1 (regular diameter $4 \mathrm{~mm}$ ) had the highest stress concentration area and highest microstrain concentration for bone tissue, dental implants, and the retaining screw $(\mathrm{P}<0.05)$. Using the PSW concept increases the area of the stress concentrations in the retaining screw $(\mathrm{P}<0.05)$ more than in the regular platform implant. It was concluded that the increase in diameter is beneficial for stress distribution and that the PSW concept had higher stress concentrations in the retaining screw and the crown compared to the regular platform implant.
\end{abstract}

(c) 2016 Elsevier B.V. All rights reserved.

\section{Introduction}

Different types of implant connections can be used for oral rehabilitation [1-3]. The identification of the best connection profile is particularly relevant to implantology. Current research seeks to determine connections that can distribute stresses more efficiently in the bone tissue and structures linked to the implant-supported prosthesis. [4,5]; peri-implant bone preservation is also a point of extensive discussion $[2,3]$.

Clinically controlled trials and systematic reviews have indicated that the use of implants with the PSW (PSW) concept can reduce periimplant bone loss [6-8]. This situation would ensure the maintenance of the gingival soft tissue and bone tissue, both of which are very important aesthetic factors $[9,10]$.

\footnotetext{
* Corresponding author at: Pró-Reitoria de Pesquisa e Pós-graduação (PRPPG), Universidade do Sagrado Coração, USC, 10-50 Irmã Arminda, Jardim Brasil, Bauru, 17011-160, SP, Brazil.

E-mail address: jf.santiagojunior@gmail.com (J.F. Santiago).
}

The platform switching concept is obtained when using a prosthetic component (abutment) that is narrower than the diameter of the implant [11]. The literature on the topic indicates that this concept can provide better preservation of the bone tissue than the regular platform can $[6,12,13]$. Furthermore, studies have suggested that this type of implant may reduce the magnitude of stress in the cortical bone [14-16].

Recent analyses of the cortical and trabecular bone tissue, which are the main focus of studies in this area, indicate that the PSW concept decreases the concentration of deformation in bone tissue around dental implants [16,17]. However, a definitive consensus on this issue has not been reached, as some reports indicate that the lowest concentration of stresses on the cortical bone may not be observed [18,19]. Furthermore, there is still not enough data in the literature to evaluate the screw and implant abutments using the PSW $[16,20]$. This issue is very important because complications in implant-supported prostheses, which are common in rehabilitation treatments-for example, screw loosening-are an unpleasant factor associated with implant rehabilitation [21].

Although studies indicate that using the PSW concept reduces the concentration of stress in the peri-implant implant region [14,15], this 
technique has some disadvantages because the prosthetic abutment reduction can result in a shift in stress in the screws and the prosthetic abutments [14] and can even lead to a fracture because of the reduction of the abutment wall. This situation would be detrimental biomechanically because it can deform the prosthetic screw beyond the material's tolerable limit of elasticity [14]. Furthermore, some biomechanical studies have indicated the possibility of greater stress concentration in the settlement region of the implant-supported prosthesis, in the abutment-implant interface, and in the platform region [22,23].

The diameter of the implant is another important factor to consider [24]. An increase in the diameter has been associated with a reduced magnitude of the stresses around the dental implants, mainly in the cortical bone $[16,19,24]$. However, there is no consensus as to the existence of an advantage from the use of the PSW concept in stress distribution for wide-diameter implants, especially in relation to the stress concentration in implant prostheses and the retaining screw [19,25].

Different types of implant connections can generate diverse biomechanical behavior. An external hexagonal implant has the advantage of reversibility $[16,26]$ and an ease of implementation with regard to the implant-supported prosthesis. Implants with external hexagonal geometry have been associated with concentrated stresses in the first threads (uppers threads) of the implant and in the implant-abutment interface [24]. On the other hand, dental implants with Morse taper connections have shown a higher stress concentration near the long axis of the implant $[16,26]$ and a better locking of the abutment with the inner surface of the implant [26], thus reducing micromovements. Therefore, there is a need to study the effect of a narrow-diameter abutment of the implant-supported prosthesis (both the PSW concept and the Morse taper) in the retaining screw. Thus, the aim of this study is to evaluate the stress distribution associated with the use of the PSW, the external hexagon, and the Morse taper connections (Fig. 1) by analyzing the effect that reducing the abutment platform has on the screw, the abutment, and the bone tissue. It is also an aim of this study to evaluate the variation in the implant's diameter ( 4 vs. $5 \mathrm{~mm}$ ) and the loading type.

The study's first null hypothesis is that the PSW concept would lead to similar values and areas of stress concentration for the fixation screws and the implant-supported prostheses compared to the implants using the regular platform. The second null hypothesis is that regular-diameter implants $(4 \mathrm{~mm})$ would present a similar stress distribution as the large-diameter implants $(5 \mathrm{~mm})$. Finally, the third null hypothesis is that the Morse taper implants would show the same stress distribution as the external hexagonal implants on bone tissue and the crown.

\section{Material and methods}

\subsection{Experimental design}

This research was designed to consider four study factors: (1) the effect of the diameter of the implants on the external hexagonal implant ( 4 vs. $5 \mathrm{~mm}$ ); (2) the effect of the different connection types: external hexagon (PSW concept or regular platform) and Morse taper; (3) the effect of the loading type: axial and oblique loading; and (4) the effect of stress distribution on the retaining screw using the PSW concept compared to an external hexagon with a regular-diameter abutment. The models are shown in Table 1.

\subsection{Description of the models}

Four models were designed for this research. The models were simulated to present a bone block with a section of trabecular and cortical bone tissue in the second molar region and a single, fixed prosthesis over the implant (Connection Implant Systems, Arujá, São Paulo, Brazil). The models were designed according to the diameters of the implants (external hexagons of 4 or $5 \mathrm{~mm}$ in diameter and $10 \mathrm{~mm}$ in length) to support a screwed crown. Also, a comparative model was designed using a Morse taper implant with the dimensions of $5 \times 10 \mathrm{~mm}$ (Connection Implant Systems, Arujá, São Paulo, Brazil). The mechanical properties of the bone tissue and the metal-ceramic crown dimensions were constant, varying only in the abutment configuration (PSW $\times$ conventional use), in accordance with Table 1 and Figs. 2 and 3.

\subsection{Metal-ceramic crown}

The external surface of the metal-ceramic crown was obtained through surface scanning of a dental mannequin's second molar, as previously described $[24,27]$. The model was finalized and simplified using Rhinoceros 4.0 software to fit into the proposed abutments [27].

\subsection{Bone tissue geometry}

The cancellous and cortical bone tissues were obtained from the decomposition of a computed tomography (CT) scan of the second molar region with the aid of InVesalius 3.0 software. The external surface of the bone tissue was simplified using 3D software (Rhinoceros 4.0) and simulated bone type III, a cortical bone with a thickness of $1 \mathrm{~mm}$ around the trabecular bone, which is commonly found in this region [28].

\subsection{Dental implants and prosthetic components}

The simulated implants were external hexagons and Morse tapers (Connection Implant Systems, Arujá, São Paulo, Brazil). The implant designs were simplified with the assistance of Solidworks 2011 software, so that the dimensions of the implants' internal and external shapes and their components could be reproduced with sufficient reliability to develop a finite element method.

The abutments were simulated using universal castable long abutment (UCLA) components (Connection Implant Systems, Arujá, São Paulo, Brazil). The component for the PSW model was simulated using a UCLA $4 \mathrm{~mm}$ in diameter in an external hexagonal implant of $5 \times 10 \mathrm{~mm}$. This abutment was similar to the implant model of $4 \times 10 \mathrm{~mm}$. A UCLA $5.0 \mathrm{~mm}$ in diameter was inserted over an external hexagonal implant of $5 \times 10 \mathrm{~mm}$ (regular use). An implant-supported prosthesis using a Morse-taper dental implant was modeled with an abutment component for the Morse taper dental implant (Connection Implant Systems, Arujá, São Paulo, Brazil).

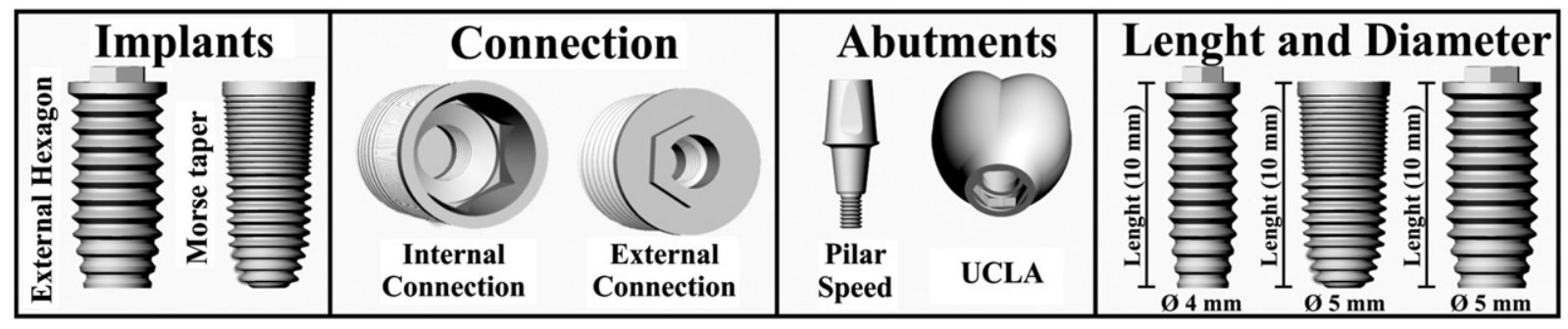

Fig. 1. Schematic drawing of the implants, connections, and abutments. 
Table 1

Description of the models.

\begin{tabular}{|c|c|c|c|}
\hline Model & Loading & Diameter & Description \\
\hline M1 & Axial & $4 \times 10$ & External hexagonal implant with screwed metal-ceramic crown, regular abutment platform. \\
\hline M2 & & $5 \times 10$ & External hexagonal implant with screwed metal-ceramic crown, regular abutment platform (wide dental implant). \\
\hline M3 & & $5 \times 10$ & External hexagonal implant with screwed metal-ceramic crown, platform switching concept (wide dental implant vs. $4.1 \mathrm{~mm}$ abutment). \\
\hline M4 & & $5 \times 10$ & Morse taper dental implant with screwed metal-ceramic crown. \\
\hline M1 & Oblique & $4 \times 10$ & External hexagonal dental implant with metal-ceramic crown screwed, regular platform. \\
\hline M2 & & $5 \times 10$ & External hexagonal dental implant with metal-ceramic crown screwed, regular platform (wide dental implant). \\
\hline M3 & & $5 \times 10$ & External hexagonal dental implant with metal-ceramic crown screwed, platform switching concept (wide dental implant). \\
\hline M4 & & $5 \times 10$ & Morse taper dental implant with metal-ceramic crown screwed. \\
\hline
\end{tabular}

Model: M.

After modeling the implants and components, all the designs were exported to the Rhinoceros 3D 4.0 software to fit the metal-ceramic crown of the molars over the designs; finally, the entire set was inserted into the bone tissue using the same software.

\subsection{Development of finite element models}

After modeling, the models were exported to a finite element program (FEMAP 11) for discretization; linear shape functions were used. Meshes were generated in each simulated structure using parabolic tetrahedral solid elements (stress elements with 10 nodes) (Fig. 3). The number of nodes for each model (M1: 506,290; M2: 407,172; M3: 443,390; M4: 575,211) and the number of elements for each model (M1: 290,918; M2: 268,800; M3: 293,720; M4: 377,627) were determined. Furthermore, the mechanical properties of the simulated materials were incorporated into each structure: cancellous bone (modulus of elasticity: $1.370 \mathrm{GPa}$; Poisson's ratio: 0.30) [29]; cortical bone (modulus of elasticity: $13.700 \mathrm{GPa}$; Poisson's ratio: 0.30) [29]; titanium (modulus of elasticity: $110 \mathrm{GPa}$; Poisson's ratio: 0.35) [30]; feldspathic porcelain (modulus of elasticity: $82.80 \mathrm{GPa}$; Poisson's ratio: 0.35) [29]; and zinc phosphate cement (modulus of elasticity: $22.4 \mathrm{GPa}$; Poisson's ratio: 0.35) [30].

The boundary conditions of the models were created in the $x, y$, and $z$ directions for the mesial and distal surfaces of the sectioned bone tissue (cortical and trabecular); the three space directions were considered fixing movements (Fig. 2). All of the contacts were simulated as bonded except for the contact between the base of the implant-abutment connection and the implant that was juxtaposed in a symmetric contact.
The loads were applied in the axial direction in relation to the long axis of the implant (200 N divided into 4 applications of $50 \mathrm{~N}$ per cusp) and in the oblique direction (100 N divided into 2 applications of $50 \mathrm{~N}$ per lingual cusp), in accordance with previous research $[16,24,31]$. The analyses were linear, and all the materials were considered isotropic, homogeneous, and linearly elastic.

\subsection{Criteria of analysis and statistical analysis}

Qualitative (maps of stress concentration) and quantitative analyses were used in this research $[4,16,31]$. Stress concentration indicates a specific area in which stress is increased and concentrated compared to other specific regions being analyzed. For the analysis of the implant types, the screw and implant-supported prosthesis used a distribution of von Mises stresses (measured in MPa) [32]. Maximum principal stress (MPS; measured in MPa) and microstrain (measured in "strain": $\mu \mathrm{m} / \mathrm{m}$, usually designed as $\mu \varepsilon$, and usually shown as "microstrain") were used for the bone tissue [16]. The data from the maps (i.e., the points with maximum stress) were organized in an Excel table (Microsoft Office Excel, Redmond, WA, USA) and were submitted to SigmaPlot software version 12.0 (SigmaPlot, San Jose, CA, USA) to be analyzed for normal distribution (Shapiro-Wilk test and equal variance) $[4,16,31]$. Subsequently, the diameter of the implant was studied using two-way analysis of variance (factors: diameter and implant region), under oblique and axial loadings. The statistical analysis of the diameter was performed by collecting the maximum values of the von Mises stress for each implant thread (10 screw threads: left and right side) of the dental implant. The 50 most representative (highest) values of the von Mises

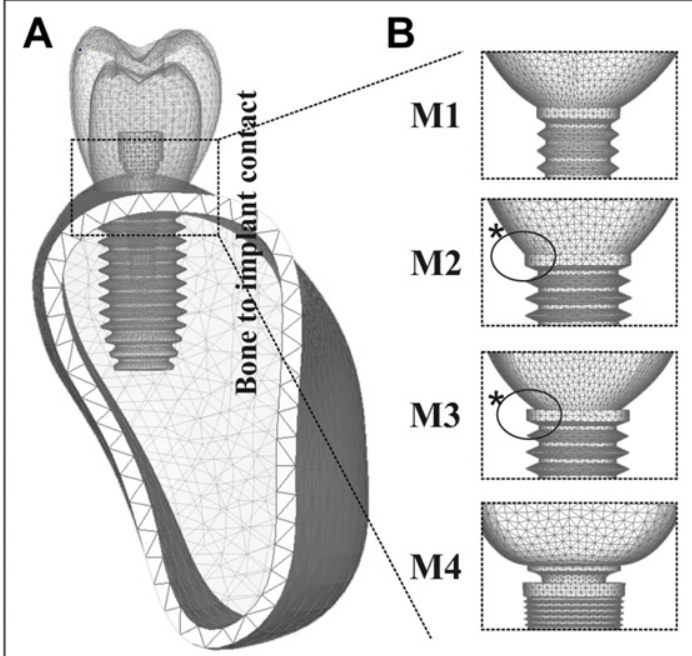

C
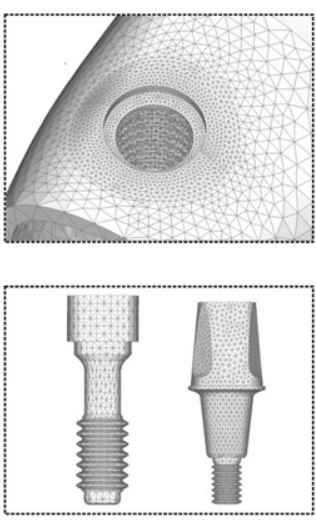

Boundary conditions

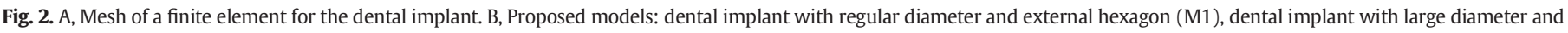

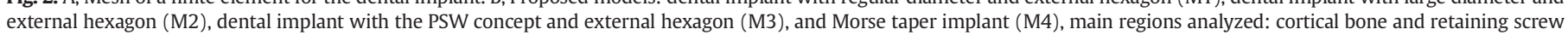
prosthesis. C, Cortical bone and abutments screw. D, Boundary conditions. Asterisk indicates change in platform. 


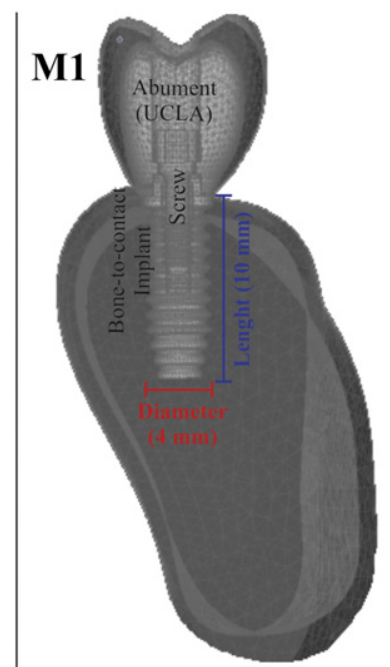

External Hexagon

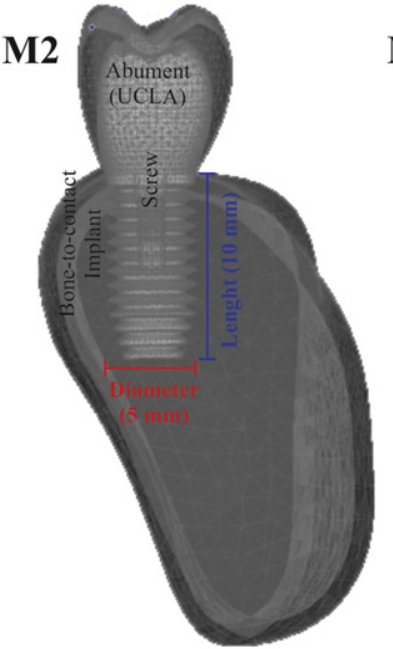

External Hexagon
M3

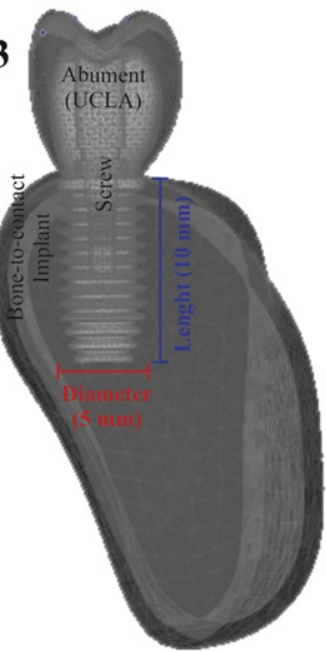

Platform Switching Concept

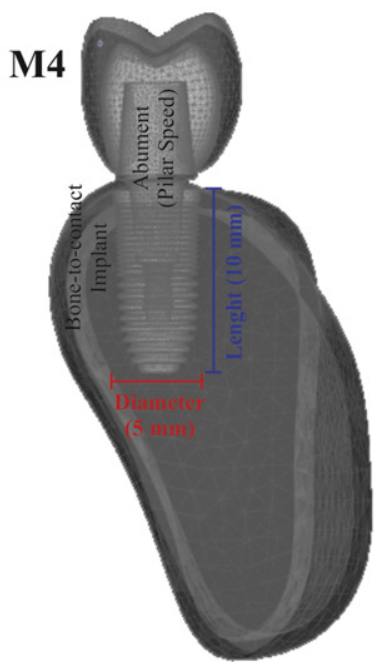

Morse Taper

Fig. 3. Finite element mesh finalized in the proposed models.

stresses in the different screws were collected to analyze the stresses in each screw. The retaining screw was assessed using a KruskalWallis one-way analysis of variance on ranks (factor: type of retaining screw of implant-supported prosthesis) under both axial and oblique loadings. For the analysis of the bone tissue, the 50 most representative values of MPS and microstrain in the different models were collected. The bone tissue in the peri-implant region was analyzed using a Kruskal-Wallis one-way analysis of variance on ranks (factor: type of connections of dental implants). The Tukey test and Dunn's method were adopted as posttests to indicate the differences between the groups, using a 5\% significance level for analysis. A linear regression and a Pearson correlation analysis were performed to compare the effect of increasing the diameter of the implant (from 4 to $5 \mathrm{~mm}$ ).

\section{Results}

\subsection{Diameter}

Analysis of the diameter factor revealed that an increase in diameter from 4 to $5 \mathrm{~mm}$ (from M1 to M2, M3, or M4) led to a distribution of stress that extended the dissipation area (dental implant) for the 5$\mathrm{mm}$ diameter models under both axial and oblique loadings. See Fig. $4 \mathrm{~A}$ and $\mathrm{B}$.

A specific analysis of the regular-diameter ( $4 \mathrm{~mm}$ ) and wide-diameter (5 mm) models of the external hexagons (M1 and M2) showed that the increase in diameter significantly favored a reduced magnitude of stress in the implant-thread region $(\mathrm{P}<0.001)$ under both axial and oblique loadings. See Fig. 4C and D.
A

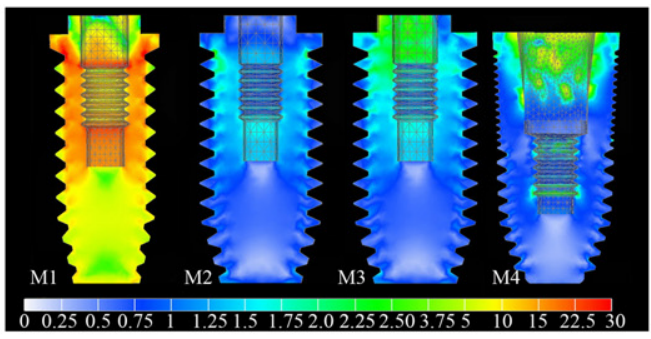

\section{Effect of implant diameter on stress distribution (axial load)}

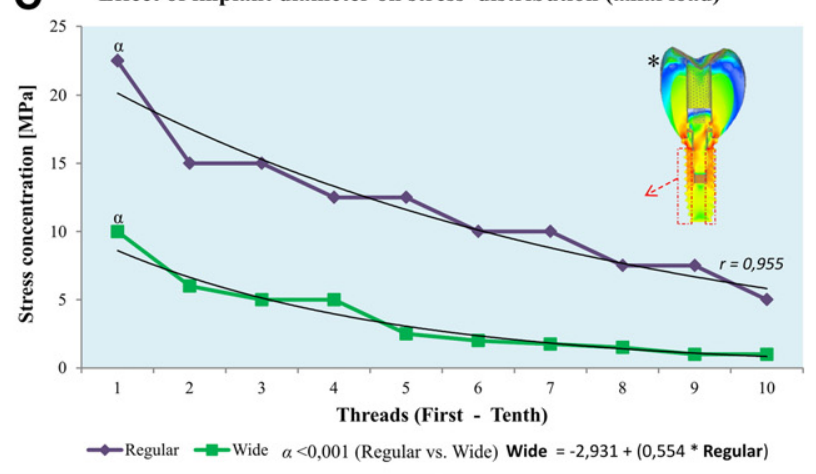

B

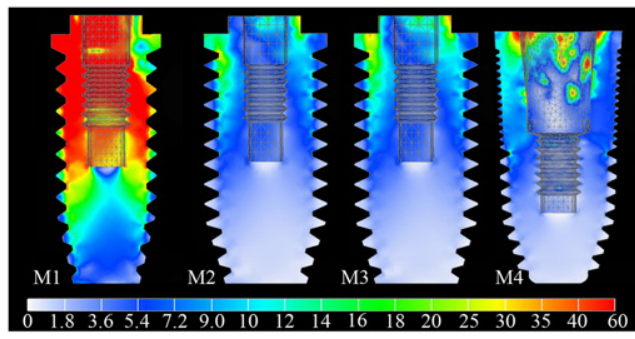

D Effect of implant diameter on stress distribution (oblique load)

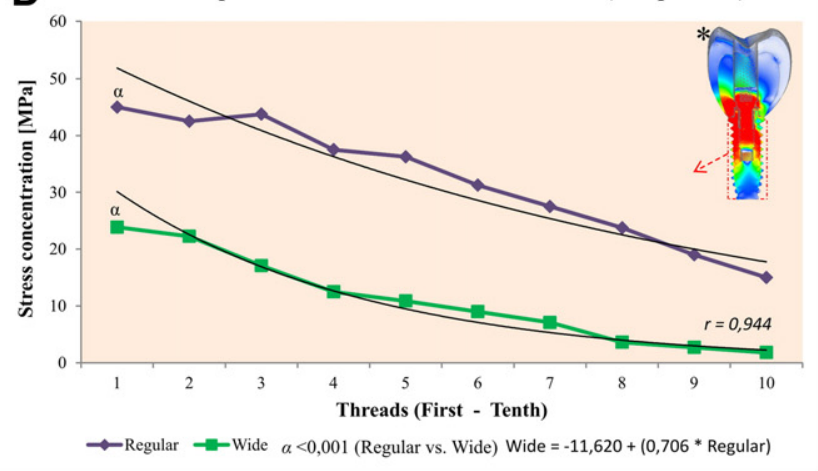

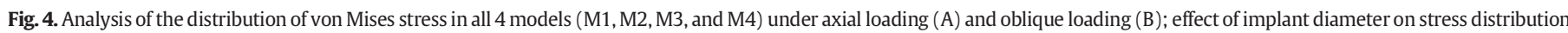
under axial loading (C) and oblique loading (D). 

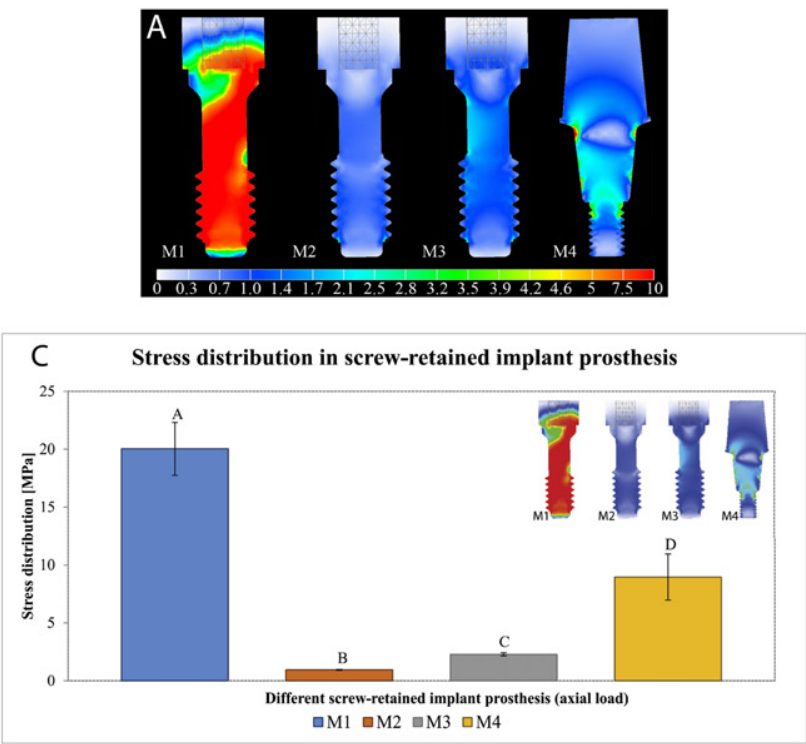
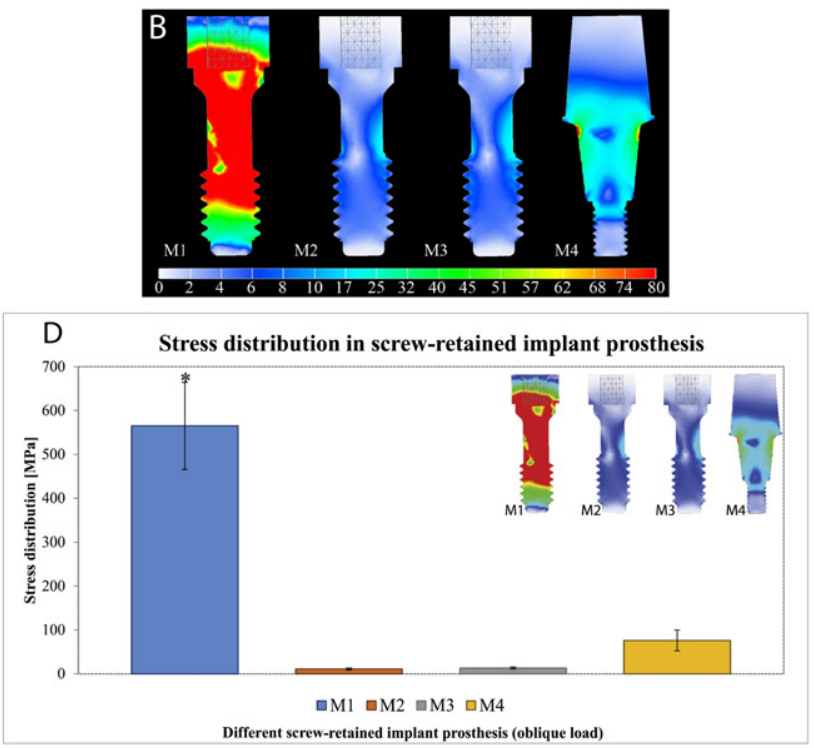

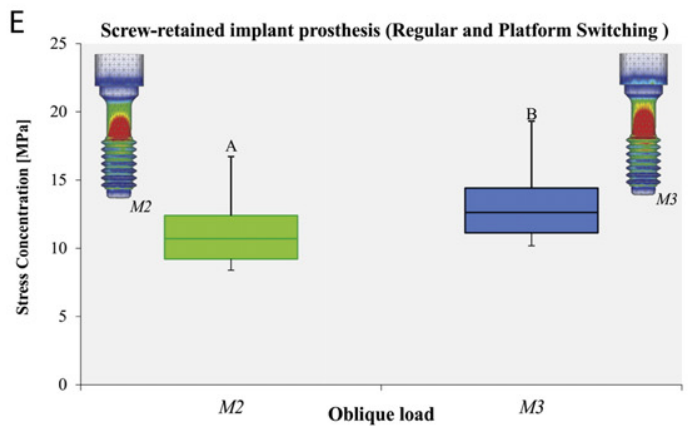

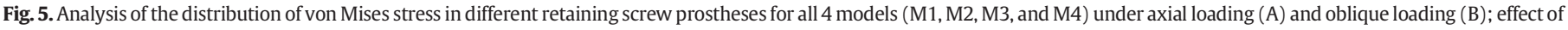
stress distribution in the retaining screw under axial loading (C) and oblique loading (D). E, effect of the retaining screw (both regular and PSW). A, B: P $<0.05$. A,B,C,D: $<<0.05$.

Under both axial and oblique loadings, the higher stress concentrations were located mainly up to the sixth thread of the implant in the regular implant and up to the fourth thread in the wide implant (Fig. 4A-D).

\subsection{Retaining screw}

In the analysis, under axial loading, the retaining screws showed greater areas of stress concentration for M1 (regular diameter), the stress extended across the screw compared to the other models (10 MPa), as shown Fig. 5A.

Under oblique loading, a higher magnitude of stress and an extended stress area were observed for all models ( $80 \mathrm{MPa}$ ) but mainly for M1 followed by M4.

A comparative analysis of M2 and M3 showed that M3 (the PSW concept) had a higher stress area in the screw, mainly near the neck area of the implant (Fig. 5A and B). This quantitative analysis confirmed the data from the previous qualitative analysis; M1 had the greatest magnitude of stresses, followed by M4 (the Morse taper), M3 (the PSW concept), and M2 (the regular platform of abutment), as shown in Table 2.

The specific analysis of the maximum stress concentrations for the retention screws under axial loading (M1-M4) showed a significant difference ( $\mathrm{P}<0.001$ ) between M1 (mean: $20.03 \mathrm{MPa}$ ) and the other models: M2 (mean: $0.94 \mathrm{MPa}$ ); M3 (mean: $2.28 \mathrm{MPa}$ ); and M4 (mean: $8.96 \mathrm{MPa}$ ). Therefore, a significant difference existed in the comparison between all the models $(\mathrm{P}<0.001)$. See Fig. 5C.

When comparing the models under oblique loading, the screw in M1 had a higher concentration of stress (mean: 565.1 MPa) than the other models (mean: M2: 11.03 MPa; M3: 13.03 MPa; M4: 76.05 MPa), with $\mathrm{P}<0.001$, according to Fig. 5D.

In a specific analysis of oblique loading, the comparison of the largediameter models showed a significant difference $(\mathrm{P}<0.001)$. Tukey's posttest identified the Morse taper dental implant as having the highest mean stress magnitude (M4: 76.05) of the models.

Table 2

Von Mises stress for different situations in screw retained prosthesis.

\begin{tabular}{|c|c|c|c|c|c|c|c|}
\hline Load & Connection & Size $(\mathrm{mm})$ & Minimum (MPa) & Median (MPa) & Average (MPa) & Standard Deviation & Maximum (MPa) \\
\hline \multirow[t]{4}{*}{ Axial } & External hexagon (M1) & $4 \times 10$ & 1.53 & 19.56 & 20.03 & 2.29 & 2.08 \\
\hline & External hexagon (M2) & $5 \times 10$ & 0.9 & 0.92 & 0.94 & 0.04 & 1.05 \\
\hline & Platform switching (M3) & $5 \times 10$ & 2.15 & 2.22 & 2.28 & 0.14 & 2.75 \\
\hline & Morse taper (M4) & $5 \times 10$ & 6.89 & 8.38 & 8.96 & 1.99 & 15.55 \\
\hline \multirow[t]{4}{*}{ Oblique } & External hexagon (M1) & $4 \times 10$ & 461.07 & 532.66 & 565.1 & 99.32 & 814.17 \\
\hline & External hexagon (M2) & $5 \times 10$ & 8.38 & 10.70 & 11.03 & 2.16 & 16.72 \\
\hline & Platform switching (M3) & $5 \times 10$ & 10.18 & 12.62 & 13.03 & 2.35 & 10.18 \\
\hline & Morse taper (M4) & $5 \times 10$ & 57.03 & 67.299 & 76.05 & 23.86 & 158.12 \\
\hline
\end{tabular}




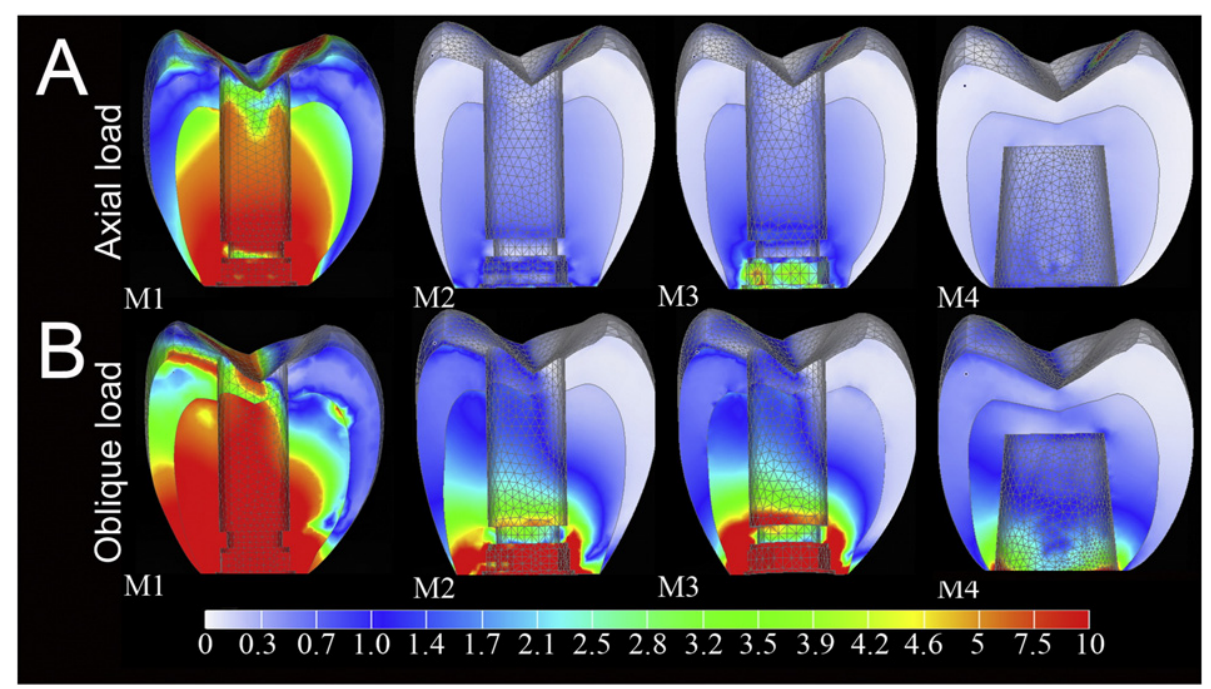

Fig. 6. Analysis of the distribution of von Mises stress in all 4 crowns (M1, M2, M3, and M4) under axial loading (A) and oblique loading (B).

In addition, the large-diameter model with the standard platform of the abutment (M2: $11.03 \mathrm{MPa}$ ) showed a significant and favorable difference in mean stress magnitude of the retaining screw relative to that of the PSW model (M3: $13.03 \mathrm{MPa}$ ), as shown in Fig. 5E.

\subsection{Crowns}

A specific analysis of the crowns showed a significant increase in the concentration of von Mises stresses for the regular-diameter model (M1) relative to the others (Fig. 6A and B). In a comparison of large-diameter models, M4 had the most favorable situation biomechanically. Furthermore, M2 (regular platform) had more favorable results than M3 (PSW) in terms of stress distribution, as shown in Fig. 6A and B.

\subsection{Bone tissue}

The stress concentration around the implants was verified in a specific analysis of the cortical bone around the implants. Data on the maximum principal stress and the microstrain were collected. In a comparative analysis of the groups, the regular-diameter model (M1) was identified as showing the greatest magnitude of stresses; this difference was statistically significant in comparison to the other groups (M2, M3, and M4) under both axial loading (mean: $1.40 \mathrm{MPa}$; $\mathrm{P}<0.05$ ) and oblique loading (mean: 20.14 MPa, $\mathrm{P}<0.05$ ), according to Table 3.

As well as the analysis of the MPS of the bone tissue, the model M1 showed a greater magnitude of microstrain than the other models (M2, M3, M4) under axial loading (mean: $1509.63 \mu \varepsilon, \mathrm{P}<0.05$ ) and oblique loading (mean: $5020.32 \mu \varepsilon, \mathrm{P}<0.05$ ), according to Table 4 . When comparing models with implants of large diameter, the most favorable result was identified as belonging to the Morse taper (M4), followed by the PSW concept (M3) and the regular platform (M2), as shown in Tables 3 and 4.

\section{Discussion}

The PSW concept has been studied using the finite elements method [18-20,23,25,33]. Studies analyzing peri-implant bone tissue have indicated some biomechanical advantage in using this type of connection $[18,20,23,33]$; in some cases, the peri-implant bone loss has already begun, and this type of connection can present a biomechanical advantage [18]. Other studies have indicated that the PSW concept has the same pattern of stress distribution as the large-diameter implant on a regular platform [19]. One of the possible disadvantages of using the implants with the PSW concept is an increase in stress in the abutments [23], but this has not been demonstrated completely in the literature [25]. This study aims to analyze the stress distribution in implants using the PSW concept and to analyze the effect this stress has on the structures of bone and the implant-supported prosthesis.

The first null hypothesis of this study was rejected because the PSW concept caused larger areas of stress concentration for the retaining screw and the implant-supported prosthesis compared to those found in the implants with the regular platform $(\mathrm{P}<0.05)$. These data confirm the indications of a previous study that showed the possibility of increased stress concentrations in structures associated with prostheses and implants that used the PSW concept [14]. On the other hand, a recently published study has indicated that the PSW concept is favorable for stress and microstrain reduction in cortical bone [16]. These data showed that, despite a favorable outcome with regard to the bone, rigorous control and maintenance of the implant-supported prostheses are required; this is because using the PSW concept shifts the stress to the area of the retaining screw and abutment, which can increase the possibility of fracture or failure in the prosthetic components $[14,33]$.

Table 3

Maximum Principal Stress in cortical bone for different models.

\begin{tabular}{|c|c|c|c|c|c|c|c|}
\hline Loading & Connection & Size & Minimum (MPa) & Median (MPa) & Average (MPa) & Standard Deviation & Maximum (MPa) \\
\hline \multirow{4}{*}{ Axial } & External hexagon (M1) & $4 \times 10 \mathrm{~mm}$ & 0.74 & 1.30 & 1.4 & 0.47 & 2.29 \\
\hline & External hexagon (M2) & $5 \times 10 \mathrm{~mm}$ & 0.05 & 0.11 & 0.12 & 0.07 & 0.34 \\
\hline & Platform switching (M3) & $5 \times 10 \mathrm{~mm}$ & 0.03 & 0.08 & 0.1 & 0.06 & 0.32 \\
\hline & Morse taper (M4) & $5 \times 10 \mathrm{~mm}$ & 0.02 & 0.03 & 0.05 & 0.05 & 0.29 \\
\hline \multirow[t]{4}{*}{ Oblique } & External hexagon (M1) & $4 \times 10 \mathrm{~mm}$ & 16.72 & 19.34 & 20.14 & 2.44 & 25.15 \\
\hline & External hexagon (M2) & $5 \times 10 \mathrm{~mm}$ & 3.38 & 4.20 & 4.51 & 0.97 & 8.17 \\
\hline & Platform switching (M3) & $5 \times 10 \mathrm{~mm}$ & 3.2 & 4.08 & 4.41 & 1.02 & 8.2 \\
\hline & Morse taper (M4) & $5 \times 10 \mathrm{~mm}$ & 2.67 & 3.10 & 3.28 & 0.57 & 5.42 \\
\hline
\end{tabular}


Table 4

Microstrain $(\mu \varepsilon)$ analysis for different models.

\begin{tabular}{|c|c|c|c|c|c|c|c|}
\hline Loading & Connection & Size $(\mathrm{mm})$ & Minimum $(\mu \varepsilon)$ & Median $(\mu \varepsilon)$ & Average $(\mu \varepsilon)$ & Standard Deviation & Maximum $(\mu \varepsilon)$ \\
\hline \multirow[t]{4}{*}{ Axial } & External hexagon (M1) & $4 \times 10$ & 1263.5 & 1484.65 & 1509.63 & 194.38 & 1840 \\
\hline & External hexagon (M2) & $5 \times 10$ & 142.68 & 159.1 & 165.35 & 20.08 & 224.27 \\
\hline & Platform switching (M3) & $5 \times 10$ & 111.03 & 124.75 & 129.7 & 18.68 & 194.57 \\
\hline & Morse taper (M4) & $5 \times 10$ & 98.61 & 112.19 & 114.87 & 12.57 & 152.36 \\
\hline \multirow[t]{4}{*}{ Oblique } & External hexagon (M1) & $4 \times 10$ & 2639.5 & 3935.15 & 5020.32 & 2199.62 & 9700.5 \\
\hline & External hexagon (M2) & $5 \times 10$ & 446.39 & 650.04 & 650.02 & 132.10 & 978.23 \\
\hline & Platform switching (M3) & $5 \times 10$ & 363.4 & 465.83 & 476.38 & 82.53 & 770.35 \\
\hline & Morse taper (M4) & $5 \times 10$ & 295.09 & 346.905 & 355.46 & 46.29 & 464.45 \\
\hline
\end{tabular}

Clinically, a recently published systematic review with a meta-analysis indicated that implants that use the PSW concept better preserve bone tissue in the peri-implant region relative to implants with a regular platform $(\mathrm{P}<0.05)$ [6]. In this study, increased complications within the area of the implant-supported prosthesis were not identified. However, it is important to emphasize that the clinical study that evaluated the PSW concept showed a reduced time to follow-up [6]. Therefore, rigorous clinical monitoring of patients is necessary, as there is the possibility of increased stresses arising in the structures associated with the implant-supported prosthesis.

The second null hypothesis was rejected because the regular-diameter implants ( $4 \mathrm{~mm}$ ) showed a higher stress concentration than the large-diameter implants $(5 \mathrm{~mm})$. A previous study qualitatively indicated that larger-diameter ( $5 \mathrm{~mm}$ ) implants had a more favorable distribution of stress than the regular-diameter implants $(4 \mathrm{~mm})$ in cortical bone [24]. The current study quantitatively indicated that the increase in the implant's diameter was a very important factor in the biomechanics of the bone tissue, the dental implant, and the retaining screw because it reduced the magnitude of the MPS and the microstrain on the bone tissue and the magnitude of the von Mises stress on the dental implant and the prosthetic components.

The third null hypothesis (that the Morse taper implants would show the same biomechanical efficiency as the external hexagonal implants) was rejected because the Morse taper implants showed better stress distribution in the cortical bone. These results are consistent with recently published studies, which have indicated the best biomechanical profile for this type of connection [4,16,34]. However, unlike previous studies that evaluated only bone tissue [16], this study indicated a significant increase in stresses among the abutments of the Morse taper implants. These results can be justified by the geometry of the Morse taper implants (an internal connection), which leads to the centralization of stresses along the axis of the implant itself and adequate stability $[4,34,35]$. Therefore, it causes an increase in stresses in the abutment-implant interface and a reduction of the magnitude of tensions in the cortical bone, as demonstrated in this study.

Thus, the best distribution of biomechanical stress in the bone tissue was accomplished through the use of the Morse taper implants. However, the biomechanical analysis does not preclude the use of external hexagonal implants with the PSW concept, as, in bone tissue, the distribution of the stresses and microstrains was more effective than it was for the regular platform. Nevertheless, the PSW concept (model 3) showed an increase in stresses in the crowns and the retaining screw; therefore, a constant clinical monitoring of these patients is needed to increase the longevity of the implant-supported prosthesis in this type of restoration to ensure an adequate control of occlusal masticatory forces.

The values of MPS measured in the bone tissue in this study (Tables 3 and 4) are below the average tolerance values registered for the bone tissue ( 72 to $76 \mathrm{MPa}$ ) tensile values [36]; the microstrain should not exceed $3000 \mu \varepsilon$ (overload) [37,38]. The most unfavorable situation involved the regular model diameter $(4 \mathrm{~mm})$ under oblique loading and microstrain (Table 4). This indicates that the larger-diameter implants have a better potential for stress distribution in the bone tissue than the regular-diameter implants do [24]; the regular-diameter implants should be used with caution, particularly in regions with high masticatory stress. Regarding the magnitude of von Mises stress identified in the retaining screw made of titanium (Ti-6Al-4V), the tension values were within a range that is limiting for tensile strength (860-965 MPa) [39], as indicated in Table 2. However, the regular-diameter model again had the highest average peak tension among the models analyzed.

Finally, the limitations of the study must be discussed. The methodology included a computer simulation, in which all of the results were identified using linear analysis in the elastic range. In the same way, all the bone tissue was simulated in the form of solid structures, as in previous studies [32,34]. All bone tissue is anisotropic [40] and nonhomogeneous, showing non-linear structures [41]. However, the literature has demonstrated that the results of FEA can be extrapolated (with caution) to the clinical daily use; all results obtained in the study should be supported by other clinical studies. Therefore, in addition to these results, it is important to conduct more relevant clinical studies on this subject and to analyze the advantages that the biomechanical results of this subject might have in clinical practice.

\section{Conclusion}

The external hexagonal implants with regular diameter $(4 \times 10 \mathrm{~mm})$ provided the most unfavorable biomechanical situation among the models tested.

For bone tissues, the Morse taper implants presented the best biomechanical results among the models $(P<0.001)$. On the other hand, this model also showed a higher stress concentration in the prosthetic abutment than the other large-diameter implants did.

The implants that used the PSW concept had higher stress concentrations in the retaining screw and the crown relative to the other large dental implants.

\section{Acknowledgements}

- State of Sao Paulo Research Foundation (FAPESP): Grant Support (2015/20827-2); Scholarship: 2015/09073-6, 2010/15734-1.

- Conselho Nacional de Desenvolvimento Científico e Tecnológico (CNPq - 303874/2010-4).

- Renato Archer Research Center, Campinas, SP, Brazil.

- Conexao Sistemas de Prótese, Arujá, São Paulo, Brazil.

\section{References}

[1] P.P. Binon, Implants and components: entering the new millennium, Int. J. Oral Maxillofac. Implants 15 (2000) 76-94.

[2] M.A. Atieh, H.M. Ibrahim, A.H. Atieh, Platform switching for marginal bone preservation around dental implants: a systematic review and meta-analysis, J. Periodontol. 81 (2010) 1350-1366.

[3] M.C. Goiato, E.P. Pellizzer, E.V. da Silva, R. Bonatto Lda, D.M. Dos Santos, Is the internal connection more efficient than external connection in mechanical, biological, and esthetical point of views? A systematic review, Oral Maxillofac. Surg. 19 (2015) 229-242.

[4] L.B. Torcato, E.P. Pellizzer, F.R. Verri, R.M. Falcon-Antenucci, J.F. Santiago Junior, D.A. de Faria Almeida, Influence of parafunctional loading and prosthetic connection on 
stress distribution: a 3D finite element analysis, J. Prosthet. Dent. 114 (2015) 644-651.

[5] A.M. Mesquita, J.H. Silva, C.H. Saraceni, A.N. Kojima, M. Özcan, Effect of different abutments and connections in deformation crestal bone, Implant. Dent. 25 (2016) 328-334.

[6] J.F.J. Santiago, V.E. de Souza Batista, F.R. Verri, H.M. Honorio, C.C. de Mello, D.A. Almeida, E.P. Pellizzer, Platform-switching implants and bone preservation: a systematic review and meta-analysis, Int. J. Oral Maxillofac. Surg. 45 (2016) 332-345.

[7] N. Enkling, P. Johren, V. Klimberg, S. Bayer, R. Mericske-Stern, S. Jepsen, Effect of platform switching on peri-implant bone levels: a randomized clinical trial, Clin. Oral Implants Res. 22 (2011) 1185-1192.

[8] N. Fernandez-Formoso, B. Rilo, M.J. Mora, I. Martinez-Silva, A.M. Diaz-Afonso, Radiographic evaluation of marginal bone maintenance around tissue level implant and bone level implant: a randomised controlled trial. A 1-year follow-up, J. Oral Rehabil. 39 (2012) 830-837.

[9] G.F. Priest, The esthetic challenge of adjacent implants, J. Oral Maxillofac. Surg. 65 (7 Suppl 1) (2007) 2-12.

[10] D.M. Gardner, Platform switching as a means to achieving implant esthetics, N. Y. State Dent. J. 71 (2005) 34-37.

[11] R.J. Lazzara, S.S. Porter, Platform switching: a new concept in implant dentistry for controlling postrestorative crestal bone levels, Int. J. Periodontics Restorative Dent. 26 (2006) 9-17.

[12] S. Annibali, I. Bignozzi, M.P. Cristalli, F. Graziani, G. La Monaca, A. Polimeni, Peri-implant marginal bone level: a systematic review and meta-analysis of studies comparing platform switching versus conventionally restored implants, J. Clin. Periodontol. 39 (2012) 1097-1113.

[13] L. Canullo, G. Goglia, G. Iurlaro, G. Iannello, Short-term bone level observations associated with platform switching in immediately placed and restored single maxillary implants: a preliminary report, Int. J. Prosthodont. 22 (2009) 277-282.

[14] Y. Maeda, J. Miura, I. Taki, M. Sogo, Biomechanical analysis on platform switching: is there any biomechanical rationale? Clin. Oral Implants Res. 18 (2007) 581-584.

[15] E.P. Pellizzer, R.M. Falcon-Antenucci, P.S. de Carvalho, J.F. Santiago, S.L. de Moraes, B.M. de Carvalho, Photoelastic analysis of the influence of platform switching on stress distribution in implants, J. Oral Implantol. 36 (2010) 419-424.

[16] J.F. Santiago Junior, F.R. Verri, Almeida, D.A. de Faria, V.E.d.S. Batista, C.A.A. Lemos, E.P. Pellizzer, Finite element analysis on influence of implant surface treatments, connection and bone types, Mater. Sci. Eng. C Mater. Biol. Appl. 63 (2016) 292-300.

[17] R.S. Pessoa, F.J. Bezerra, R.M. Sousa, J. Vander Sloten, M.Z. Casati, S.V. Jaecques, Biomechanical evaluation of platform switching: different mismatch sizes, connection types, and implant protocols, J. Periodontol. 85 (2014) 1161-1171.

[18] H. Xia, M. Wang, L. Ma, Y. Zhou, Z. Li, Y. Wang, The effect of platform switching on stress in peri-implant bone in a condition of marginal bone resorption: a three-dimensional finite element analysis, Int. J. Oral Maxillofac. Implants 28 (2013) e122-e127.

[19] E.P. Pellizzer, F.R. Verri, R.M. Falcon-Antenucci, J.F. Junior, P.S. de Carvalho, S.L. de Moraes, P.Y. Noritomi, Stress analysis in platform-switching implants: a 3-dimensional finite element study, J. Oral Implantol. 38 (2012) 587-594.

[20] S. Paul, T.V. Padmanabhan, S. Swarup, Comparison of strain generated in bone by "platform-switched" and "non-platform-switched" implants with straight and angulated abutments under vertical and angulated load: a finite element analysis study, Indian J. Dent. Res. 24 (2013) 8-13.

[21] A. Bacchi, A. Regalin, C.L. Bhering, R. Alessandretti, A.O. Spazzin, Loosening torque of universal abutment screws after cyclic loading: influence of tightening technique and screw coating. J. Adv. Prosthodont. 7 (2015) 375-379.

[22] I. Tanasic, L. Tihacek-Sojic, A. Milic-Lemic, Finite element analysis of compressive stress and strain of different implant forms during vertical loading, Int. J. Comput. Dent. 17 (2014) 125-133.

[23] S. Liu, C. Tang, J. Yu, W. Dai, Y. Bao, D. Hu, The effect of platform switching on stress distribution in implants and periimplant bone studied by nonlinear finite element analysis, J. Prosthet. Dent. 112 (2014) 1111-1118.
[24] J.F. Santiago Junior, E.P. Pellizzer, F.R. Verri, P.S. de Carvalho, Stress analysis in bone tissue around single implants with different diameters and veneering materials: a $3-$ D finite element study, Mater. Sci. Eng. C Mater. Biol. Appl. 33 (2013) 4700-4714.

[25] A. Alvarez-Arenal, L. Segura-Mori, I. Gonzalez-Gonzalez, A. Gago, Stress distribution in the abutment and retention screw of a single implant supporting a prosthesis with platform switching, Int. J. Oral Maxillofac. Implants 28 (2013) e112-e121.

[26] M.S. Pita, R.B. Anchieta, V.A. Barao, I.R. Garcia Jr., V. Pedrazzi, W.G. Assuncao, Prosthetic platforms in implant dentistry, J. Craniofac. Surg. 22 (2011) 2327-2331.

[27] R.M. Falcon-Antenucci, E.P. Pellizzer, P.S. de Carvalho, M.C. Goiato, P.Y. Noritomi, Influence of cusp inclination on stress distribution in implant-supported prostheses. A three-dimensional finite element analysis, J. Prosthodont. 19 (2010) 381-386.

[28] U. Lekholm, G.A. Zarb, Patient Selection and Preparation. in: PI Branemark, GA Zarb (Eds.), Tissue integrated prostheses: osseointegration in clinical dentistry, Quintessence Publishing Company, Chicago 1985, pp. 199-209.

[29] A. Sertgoz, Finite element analysis study of the effect of superstructure material on stress distribution in an implant-supported fixed prosthesis, Int. J. Prosthodont. 10 (1997) 19-27.

[30] K.J. Anusavice, B. Hojjatie, Stress distribution in metal-ceramic crowns with a facial porcelain margin, J. Dent. Res. 66 (1987) 1493-1498.

[31] F. Ramos Verri, J.F. Santiago Junior, D.A. de Faria Almeida, G.B. de Oliveira, V.E. de Souza Batista, H. Marques Honorio, P.Y. Noritomi, E.P. Pellizzer, Biomechanical influence of crown-to-implant ratio on stress distribution over internal hexagon short implant: 3-D finite element analysis with statistical test, J. Biomech. 48 (2015) $138-145$.

[32] F.R. Verri, V.E. Batista, J.F. Santiago Jr., D.A. Almeida, E.P. Pellizzer, Effect of crown-toimplant ratio on peri-implant stress: a finite element analysis, Mater. Sci. Eng. C Mater. Biol. Appl. 45 (2014) 234-240.

[33] C.L. Chang, C.S. Chen, M.L. Hsu, Biomechanical effect of platform switching in implant dentistry: a three-dimensional finite element analysis, Int. J. Oral Maxillofac. Implants 25 (2010) 295-304.

[34] D.A. de Faria Almeida, E.P. Pellizzer, F.R. Verri, J.F. Santiago Jr., P.S. de Carvalho, Influence of tapered and external hexagon connections on bone stresses around tilted dental implants: three-dimensional finite element method with statistical analysis, J. Periodontol. 85 (2014) 261-269.

[35] A.C. Dayrell, P.Y. Noritomi, J.M. Takahashi, R.L. Consani, M.F. Mesquita, M.B. dos Santos, Biomechanical analysis of implant-supported prostheses with different implant-abutment connections, Int. J. Prosthodont. 28 (2015) 621-623.

[36] G. Papavasiliou, P. Kamposiora, S.C. Bayne, D.A. Felton, Three-dimensional finite element analysis of stress-distribution around single tooth implants as a function of bony support, prosthesis type, and loading during function, J. Prosthet. Dent. 76 (1996) 633-640.

[37] H.M. Frost, Bone's mechanostat: a 2003 update, Anat. Rec. A: Discov. Mol. Cell. Evol Biol. 275 (2003) 1081-1101.

[38] M.B. dos Santos, A. Bacchi, L. Correr-Sobrinho, R.L. Consani, The influence of clip material and cross sections of the bar framework associated with vertical misfit on stress distribution in implant-retained overdentures, Int. J. Prosthodont. 27 (2014) 26-32.

[39] M. Geetha, A.K. Singh, R. Asokamani, A.K. Gogia, Ti based biomaterials, the ultimate choice for orthopaedic implants - a review, Prog. Mater. Sci. 397-425 (2009).

[40] LJ. Fuh, J.T. Hsu, H.L. Huang M.Y. Chen, Y.W. Shen, Biomechanical investigation of thread designs and interface conditions of zirconia and titanium dental implants with bone: three-dimensional numeric analysis, Int. J. Oral Maxillofac. Implants 28 (2013) e64-e71.

[41] M.B. Ferreira, V.A. Barão, J.A. Delben, L.P. Faverani, A.C. Hipólito, W.G. Assunção, Non-linear 3D finite element analysis of full-arch implant-supported fixed dentures, Mater. Sci. Eng. C Mater. Biol. Appl. 38 (2014) 306-314. 